\title{
Uterine Clear Cell Carcinoma of Postmenopausal Woman: A Case Report
}

\author{
Soo-Ho Chung', Jung-Woo Park² \\ ${ }^{1}$ Department of Obstetrics and Gynecology, Soonchunhyang University College of Medicine, Bucheon, ${ }^{2}$ Department of Obstetrics and \\ Gynecology, Dong-A University College of Medicine, Busan, Korea
}

Endometrial cancer is the most common gynecologic malignancy in developed countries. Clear cell carcinoma typically occurs in the ovaries, and very rarely occurs in the endometrium; it accounts for less than $3 \%$ of all endometrial cancers. It is presumed that clear cell carcinomas are of Müllerian duct origin, and an association with exposure to diethylstilbestrol (DES) or other nonsteroidal follicle stimulating hormones has been described. We report a case of a postmenopausal woman who presented with vaginal bleeding without a specific medical history. Under the impression of an endometrial mass, we performed a laparoscopic operation. Pathologic results showed clear cell carcinoma of the endometrium. Depth of invasion was $0.2 \mathrm{~cm}$ out of a $0.5 \mathrm{~cm}$ total thickness, and the rectal shelf mass was clear cell carcinoma. We report the case with a brief review of the relevant literature. (J Menopausal Med 2016;22:122-125)

Key Words: Adenocarcinoma · Clear cell · Endometrial neoplasms · Postmenopause

\section{Introduction}

Endometrial cancer is the most common gynecologic malignancy in developed countries, and its incidence has more than doubled over the last 10 years in Korea. ${ }^{1}$ Clear cell carcinoma typically occurs in the ovaries, is rarely seen in the cervix or vagina, and very rarely occurs in the endometrium, accounting for less than $3 \%$ of all endometrial cancers. ${ }^{2}$ Clear cell carcinoma is characterized by abundant cytoplasm like in clear cell renal cell carcinoma and clear hobnail cells, ${ }^{3}$ and it is presumed that clear cell carcinomas are of Müllerian duct origin. ${ }^{3}$ Since the study reported by Herbst and Scully ${ }^{4}$ in 1970, the association of exposure to diethylstilbestrol (DES) or other nonsteroidal follicle stimulating hormones has been described. The authors experienced a rare case of a 66-year-old woman who visited our hospital due to vaginal bleeding without a specific history and we report the case with a brief review of literature.

\section{Case Report}

A 66-year-old woman (141 cm, $46 \mathrm{~kg}$, body mass index [BMI] $23.2 \mathrm{~kg} / \mathrm{m}^{2}$ ), gravida 3 was admitted to our Obstetrics \& Gynecology hospital, and her chief complaint was vaginal spotting which occurred a month ago. She had hypertension and took medical therapy. Under the impression of endometrial mass, tumor marker, complete blood cell count, serum chemistry, ultrasound sonography (USG), hysteroscopy were done. Cancer antigen 125 (CA-125) is $22.5 \mathrm{U} / \mathrm{mL}$, USG image showed large mass in endometrial

Received: March 28, 2016 Revised: May 26, 2016 Accepted: May 31, 2016

Address for Correspondence: Jung-Woo Park, Department of Obstetrics and Gynecology, Dong-A University College of Medicine, 26 Daesingongwon-ro, Seo-gu, Busan 49201, Korea

Tel: +82-51-240-2957, Fax: +82-51-244-9553, E-mail: mdpjw1216@gmail.com 
cavity and hysteroscopic biopsy result is clear cell carcinoma (Fig. 1). Positron emission tomography (PET)-computed tomography (CT) image showed diffuse heterogeneous hypermetabolic lesion in the endometrial cavity and focal hypermetabolic lesion between the right aspect of rectum and uterus (Fig. 2). Laparoscopic assisted hysterectomy with bilateral salpingo-oophorectomy (BSO), pelvic lymph node dissection and rectal shelf mass removal was done (Fig. 2). Pathologic report was clear cell carcinoma of the endometrium, depth of invasion was $0.2 \mathrm{~cm}$ out of 0.5 $\mathrm{cm}$ thickness, rectal shelf mass was clear cell carcinoma. Postoperative radiotherapy was performed and the patient is currently under outpatient follow-up with subclinical conditions,

\section{Discussion}

Endometrial cancer is the seventh most common type of cancer among women, accounting for 3.9\% of all cancers and $1.7 \%$ of all cancer deaths in women. ${ }^{5}$ Although prevalence rates vary according to studies, clear cell carcinoma represents about $3 \%$ of all endometrial carcinomas. ${ }^{6,7}$

Clear cell carcinomas developing in any of the female reproductive organs are identical in cytological variants, histological patterns and ultrastructure. Since the descriptive term clear cell carcinoma originating from the Müllerian duct was first introduced by Scully and Barlow in 1967, it is generally accepted that clear cell carcinoma is developmentally derived from the Müllerian duct. ${ }^{8}$ Although the exact cause or pathogenesis has not yet been clarified, multiple risk factors have been suggested including DES use
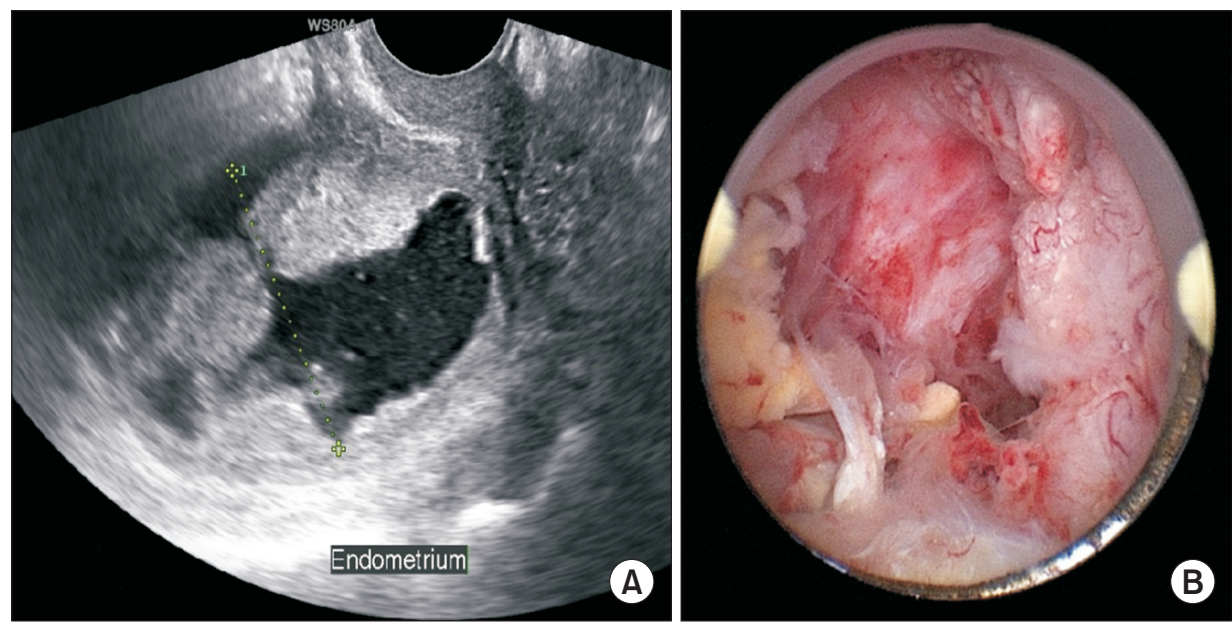

Fig. 1. (A) Ultrasound sonography findings showing an endometria mass. (B) Hysteroscopic findings in the endometrial cavity.
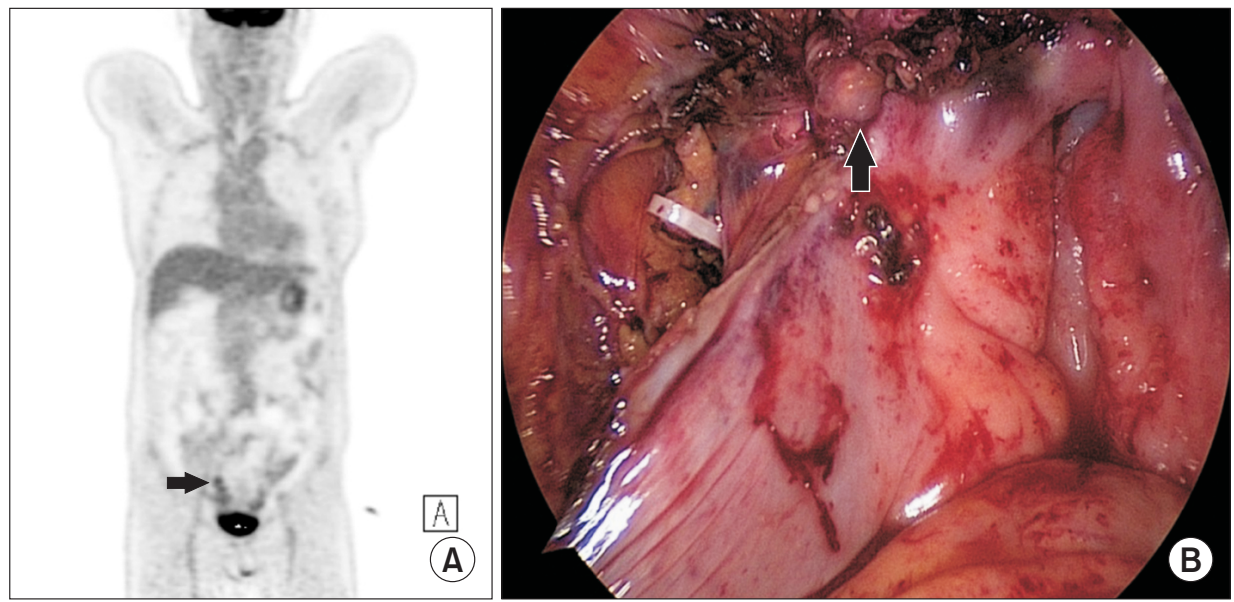

Fig. 2. (A) Positron emission tomography (PET)-computed tomography (CT) image showing a focal hypermetabolic lesion between the right aspect of the rectum and the uterus $(\rightarrow)$. (B) Laparoscopic findings showing a rectal shelf mass $(\uparrow)$. 
during pregnancy, genetic predisposing factors, instability of microsatellite repeat sequences, human papilloma virus infection, overexpression of B-cell lymphoma 2 (Bcl2) protein, variation of the p53 gene, and external or environmental factors. ${ }^{9}$ However, clear cell carcinoma of the endometrium like the case in this study is rarely seen, and has not been detected in children of mothers who took DES in some previous studies. ${ }^{10}$ The present study was unable to identify the exact cause associated with DES exposure or genetic predisposing factors.

Most common symptoms are vaginal discharge or vaginal bleeding lasting for several weeks or years, and most underling disease are hypertension, diabetes, obesity or other symptom may be associated. Although these symptoms align with the triggers of endometrial cancer, this finding has not yet been confirmed.

Clear cell cancer is often diagnosed by sonographic appearance of endometrial tumors or endometrial biopsy when the above symptoms are associated.

Photopulus classified 22 cases of clear cell carcinoma of the endometrium according to the extent of involvement, and their clinical stages were stage I, 23\%; stage II, 50\%; and stages III and IV, 27\%. ${ }^{6}$ In the case of this study, although invasion was confined to less than half of the endometrium, stage III was confirmed as clear cell carcinoma was found in tumors of the rectal shelf having high PET signal.

Like most other endometrial cancers, total laparoscopic hysterectomy (TLH), BSO and radiation therapy are considered as treatment options, and only TLH and BSO can be performed or radiation therapy can be added for treatment of early-stage endometrial clear cell carcinoma. The addition of radiation therapy is not the exact protocol, and its definite roles still remain controversial. This is because that this therapy is used infrequently and radiation doses and methods vary according to institutions. A recent study on the addition of chemotherapy addressed that the addition of radiation therapy had no influence on survival rate and chemotherapy was more effective. ${ }^{2}$

Clear cell carcinoma is characterized by late recurrence compared to other carcinomas. Recurrences typically occur 17 months after primary treatment, and are seen in about $21 \%$ of patients 5 years later. ${ }^{11}$

This type of tumor is suggested to have a relatively poor prognosis compared to other endometrial cancers according to our literature review. ${ }^{3,6,10}$ Photoplus proposed that poor prognosis was attributable to a higher frequency of poorlydifferentiated tumors in clear cell carcinoma. ${ }^{6}$ For this reason, clear cell carcinoma is currently classified as grade 3 (poorly differentiated), and surgical procedure and radiation therapy or chemotherapy should be performed. However, this type of carcinoma shows poorer prognosis compared to the prognosis of grade 3 endometrial carcinomas, and the 5-year survival rates range from $40 \%$ to $54 \%$ between those of stage III-IV endometrioid cancer and clear cell carcinoma. ${ }^{2}$ Thus, active and radical treatment is warranted. The authors experienced a clear cell carcinoma of the endometrium (stage IIIB), and we report the case with a brief review of literature.

\section{Conflict of Interest}

No potential conflict of interest relevant to this article was reported.

\section{References}

1. Lim MC, Moon EK, Shin A, Jung KW, Won YJ, Seo SS, et al. Incidence of cervical, endometrial, and ovarian cancer in Korea, 1999-2010. J Gynecol Oncol 2013; 24: 298-302.

2. Hamilton CA, Cheung MK, Osann K, Chen L, Teng NN, Longacre TA, et al. Uterine papillary serous and clear cell carcinomas predict for poorer survival compared to grade 3 endometrioid corpus cancers. Br J Cancer 2006; 94: 642-6.

3. Silverberg SG, De Giorgi LS. Clear cell carcinoma of the endometrium. Clinical, pathologic, and ultrastructural findings. Cancer 1973; 31: 1127-40.

4. Herbst AL, Scully RE. Adenocarcinoma of the vagina in adolescence. A report of 7 cases including 6 clear-cell carcinomas (so-called mesonephromas). Cancer 1970; 25: 745-57.

5. Parkin DM, Bray F, Ferlay J, Pisani P. Global cancer statistics, 2002. CA Cancer J Clin 2005; 55: 74-108.

6. Photopulos GJ, Carney CN, Edelman DA, Hughes RR, Fowler WC, Jr., Walton LA. Clear cell carcinoma of the endometrium. Cancer 1979; 43: 1448-56.

7. Park JW, Hwang SO. Abdominal wall metastasis of uterine papillary serous carcinoma in a post-menopausal woman: 
a case report. J Menopausal Med 2014; 20: 35-8.

8. Heo EJ, Park JM, Lee EH, Lee HW, Kim MK. A case of perimenopausal endometrial cancer in a woman with MSH2 germline mutation. J Menopausal Med 2013; 19: 143-6.

9. Reich O, Pürstner P, Klaritsch P, Haas J, Lahousen M, Tamussino K, et al. Prognostic significance of preoperative DNA flow cytometry in surgically-treated cervical cancer. Eur J Gynaecol Oncol 2003; 24: 13-7.
10. Christopherson WM, Alberhasky RC, Connelly PJ. Carcinoma of the endometrium: I. A clinicopathologic study of clear-cell carcinoma and secretory carcinoma. Cancer 1982; 49: 1511-23.

11. Bae HS, Kim H, Young Kwon S, Kim KR, Song JY, Kim I. Should endometrial clear cell carcinoma be classified as Type II endometrial carcinoma? Int J Gynecol Pathol 2015; 34: 74-84. 